\title{
Regulation of Cytosolic Sulfotransferases in Models of Human Hepatocyte Development ${ }^{\mathbb{S}}$
}

\author{
Sarah Dubaisi, Kathleen G. Barrett, Hailin Fang, Jorge Guzman-Lepe, Alejandro Soto-Gutierrez, \\ Thomas A. Kocarek, and Melissa Runge-Morris
}

Department of Pharmacology (S.D.) and Institute of Environmental Health Sciences (K.G.B., H.F., T.A.K., M.R.-M.), Wayne State University, Detroit, Michigan; and Department of Pathology, University of Pittsburgh, Pittsburgh, Pennsylvania (J.G.-L., A.S.-G.)

Received March 12, 2018; accepted May 17, 2018

\begin{abstract}
Cytosolic sulfotransferases (SULTs) are expressed during early life and therefore metabolize endogenous and xenobiotic chemicals during development. Little is currently known about the regulation of individual SULTs in the developing human liver. We characterized SULT expression in primary cultures of human fetal hepatocytes and the HepaRG model of liver cell differentiation. SULT1A1 (transcript variants 1-4), SULT1C2, SULT1C4, SULT1E1, and SULT2A1 were the most abundant transcripts in human fetal hepatocytes. In HepaRG cells, SULT1B1, SULT1C2/3/4, and SULT1E1 mRNA levels increased during the transition from proliferation to confluency and then decreased as the cells underwent further differentiation. By contrast, SULT2A1 mRNA levels increased during differentiation, whereas SULT1A1 and SULT2B1 mRNA levels remained relatively constant. The temporal patterns of SULT1C2, SULT1E1, and SULT2A1 protein content were consistent with those observed at
\end{abstract}

the mRNA level. To identify regulators of SULT expression, cultured fetal hepatocytes and HepaRG cells were treated with a panel of lipid- and xenobiotic-sensing receptor activators. The following effects were observed in both fetal hepatocytes and HepaRG cells: 1) liver $X$ receptor activator treatment increased SULT1A1 transcript variant 5 levels; 2) vitamin $D$ receptor activator treatment increased SULT1C2 and SULT2B1 mRNA levels; and 3) farnesoid $X$ receptor activator treatment decreased SULT2A1 expression. Activators of aryl hydrocarbon receptor, constitutive androstane receptor, pregnane $X$ receptor, and peroxisome proliferator-activated receptors produced additional gene-dependent effects on SULT expression in HepaRG cells. These findings suggest that SULTregulating chemicals have the potential to modulate physiologic processes and susceptibility to xenobiotic stressors in the developing human liver.

\section{Introduction}

As the primary organ responsible for maintaining metabolic homeostasis, the liver metabolizes both endogenous and xenobiotic molecules. The xenobiotic-metabolizing capacity of the immature human liver is different from that of the adult. Selected xenobiotic-metabolizing enzymes are expressed during early life, and these likely influence the susceptibility of the developing human to the effects of drugs and environmental chemicals (Barker et al., 1994; Miki et al., 2002; Duanmu et al., 2006; Hines, 2007; Sadler et al., 2016). Characterizing the developmental expression of xenobiotic-metabolizing enzymes is essential for understanding the impact of the environment on human health.

This research was supported by the National Institutes of Health National Institute of Environmental Health Sciences [Grants R01-ES-022606 (to M.R.-M.), Center Grant P30- ES-020957], and National Institutes of Health National Institute of Diabetes and Digestive and Kidney Diseases [Grant R01 DK099257 (to A.S.-G.)].

https://doi.org/10.1124/dmd.118.081398.

SThis article has supplemental material available at dmd.aspetjournals.org.
The cytosolic sulfotransferases (SULTs) catalyze the conjugation of a sulfonate moiety to a wide variety of xenobiotic and endogenous substrates that include hormones, neurotransmitters, and sterols (Falany et al., 1995; Li et al., 2000; Pai et al., 2002; Allali-Hassani et al., 2007). Addition of the charged sulfonate group makes a substrate more hydrophilic, which facilitates its elimination from the body. Sulfate conjugation can also cause prodrug activation (e.g., minoxidil) (Johnson et al., 1983; Hirshey and Falany, 1990), hormone inactivation (e.g., estradiol) (Falany et al., 1995), and pro-carcinogen bioactivation (e.g., $N$-hydroxy-2-acetylaminofluorene) (Sakakibara et al., 1998).

There are 13 human SULT genes, which are classified into four families. Some SULTs are expressed during early development, indicating that these enzymes contribute to metabolism during fetal life (Barker et al., 1994; Forbes et al., 1995; Her et al., 1997; Stanley et al., 2005; Duanmu et al., 2006). We previously reported that SULT1A1, SULT1E1, and SULT2A1 are expressed in fetal liver, with each enzyme displaying a distinctive pattern of developmental expression (Duanmu et al., 2006). Although hepatic SULT1A1 expression remained relatively constant from prenatal life through adulthood, SULT1E1 was most highly expressed during early life and SULT2A1 expression was higher in the adult.

ABBREVIATIONS: AhR, aryl hydrocarbon receptor; CDCA, chenodeoxycholate; CITCO, 6-(4-chlorophenyl)imidazo[2,1-b][1,3]thiazole-5-carbaldehyde O-(3,4-dichlorobenzyl)oxime; $C_{t}$, cycle threshold; DMSO, dimethylsulfoxide; FXR, farnesoid X receptor; GW3965, 3-[3-[[[2-chloro-3-(trifluoromethyl)phenyl]methyl](2,2-diphenylethyl)amino]propoxy]benzeneacetic acid hydrochloride; GW4064, 3-[2-[2-chloro-4-[[3-(2,6-dichlorophenyl)-5-(1-methylethyl)4-isoxazolyl]methoxy]phenyl]ethenyl]benzoic acid; GW7647, 2-[[4-[2-[[(cyclohexylamino)carbonyl](4-cyclohexylbutyl)amino]ethyl]phenyl] thio]-2-methylpropanoic acid; LXR, liver X receptor; PPAR, peroxisome proliferator-activated receptor; PXR, pregnane X receptor; SULT, cytosolic sulfotransferase; TCDD, 2,3,7,8-tetrachlorodibenzo- $p$-dioxin; TV, transcript variant; VDR, vitamin D receptor; VitD ${ }_{3}$, $1 \alpha, 25$ dihydroxyvitamin $D_{3}$. 
SULT expression is regulated by lipid- and xenobiotic-sensing receptors, including aryl hydrocarbon receptor (AhR), constitutive androstane receptor, pregnane $\mathrm{X}$ receptor (PXR), liver $\mathrm{X}$ receptor (LXR), farnesoid $\mathrm{X}$ receptor (FXR), peroxisome proliferator-activated receptors (PPARs), and vitamin D receptor (VDR) in a species- and tissue-specific manner (Echchgadda et al., 2004a,b; Fang et al., 2005, 2007; Jiang et al., 2005; Fu et al., 2011; Kodama et al., 2011; Sueyoshi et al., 2011). Most studies of human SULT regulation have been performed using primary cultures of adult human hepatocytes (Fang et al., 2005, 2007; Uppal et al., 2007), or hepatic or extrahepatic cell lines (Song et al., 2001; Higashi et al., 2004; Jiang et al., 2005; Fu et al., 2011; Rondini et al., 2014; Barrett et al., 2016; Dubaisi et al., 2016), but none have been performed using human fetal hepatocytes or culture models of human liver cell differentiation. Consequently, little is known about the mechanisms that regulate SULT expression during human liver development.

The HepaRG cell line was derived from an Edmonson grade I differentiated hepatocellular carcinoma. It has been classified as a bipotent hepatic progenitor cell line that can be differentiated into both cholangiocyte-like and hepatocyte-like cells (Parent et al., 2004). Many studies have demonstrated that HepaRG-derived hepatocytelike cells exhibit properties of adult human hepatocytes, including the expression of xenobiotic-metabolizing enzymes, transporters, and the transcription factors that control hepatocellular gene expression (Aninat et al., 2006; Lubberstedt et al., 2011; Gerets et al., 2012; Hoekstra et al., 2013; Tsuji et al., 2014). Undifferentiated and differentiated HepaRG cells have distinct gene expression profiles that tend to reflect the patterns seen in fetal and adult human liver, respectively. Genes that are primarily expressed in fetal hepatocytes, such as CYP3A7 and pyruvate kinase muscle isozyme, are more highly expressed in undifferentiated HepaRG cells, whereas genes that are predominantly expressed in adult hepatocytes, such as CYP3A4 and CYP2E1, are more highly expressed in differentiated HepaRG cells (Tsuji et al., 2014; Bucher et al., 2017). HepaRG cells are becoming established as a useful model for studying hepatocellular differentiation, xenobiotic metabolism and toxicity, and development of liver diseases (Sharanek et al., 2015; Nunn et al., 2016; Rodrigues et al., 2016; Sayyed et al., 2016; Xia et al., 2016). In this study, we have defined the temporal patterns of SULT expression in HepaRG cells during differentiation. We have also determined the effects of treatments with activators of lipid- and xenobiotic-sensing receptors on SULT expression in undifferentiated and differentiated HepaRG cells as well as in primary cultures of human fetal hepatocytes.

\section{Materials and Methods}

Materials. Cell culture media and supplements (except insulin) were purchased from Invitrogen (Carlsbad, CA). Human recombinant insulin (Novolin R) was purchased from Novo Nordisk Pharmaceuticals, Inc. (Princeton, NJ). 3-[2-[2-Chloro-4-[[3-(2,6-dichlorophenyl)-5-(1-methylethyl)-4-isoxazolyl]methoxy]phenyl]ethenyl]benzoic acid (GW4064; purity $\geq 97 \%)$ and 2-[[4-[2-[[(cyclohexylamino)carbonyl](4-cyclohexylbutyl)amino]ethyl]phenyl]thio]-2-methylpropanoic acid (GW7647; purity $\geq 99 \%$ ) were purchased from Tocris Bioscience (Minneapolis, MN). Chenodeoxycholate (CDCA; purity $\geq 97 \%$ ), 6-(4-chlorophenyl)imidazo[2,1-b][1,3]thiazole-5-carbaldehyde O-(3,4-dichlorobenzyl)oxime (CITCO; purity $\geq 98 \%$ ), rosiglitazone (purity $\geq 98 \%$ ), rifampicin (purity $\geq 97 \%$ ), $1 \alpha, 25$ dihydroxyvitamin $\mathrm{D}_{3}\left(\mathrm{VitD}_{3}\right.$; purity $\geq 99 \%$ ), 3-[3-[[[2-chloro-3-(trifluoromethyl)phenyl]methyl](2,2-diphenylethyl)amino]propoxy]benzeneacetic acid hydrochloride (GW3965; purity $\geq 98 \%$ ), and dimethylsulfoxide (DMSO) were purchased from Sigma-Aldrich (St. Louis, MO), and 2,3,7,8- tetrachlorodibenzo-p-dioxin (TCDD; purity $\sim 98 \%$ ) was purchased from Midwest Research Institute (Kansas City, $\mathrm{MO})$. Other materials were obtained from the sources indicated below.

HepaRG Culture and Treatments. HepaRG cells were obtained from Biopredic International (Saint Grégoire, France) under a Material Transfer Agreement with INSERM-Transfert (Paris, France). Cells were plated into sixwell plates at a density of 250,000 cells/well in growth medium consisting of
Williams' Medium E supplemented with $10 \%$ fetal bovine serum, $5 \mu \mathrm{g} / \mathrm{ml}$ insulin, $0.1 \mu \mathrm{M}$ triamcinolone acetonide, $100 \mathrm{U} / \mathrm{ml}$ penicillin, and $100 \mu \mathrm{g} / \mathrm{ml}$ streptomycin. Fourteen days after plating, the medium was changed to differentiation medium, consisting of growth medium with $2 \%$ DMSO, and the cells were incubated for 14 more days, with medium replenishment every 2-3 days. Differentiated HepaRG cells were then incubated in treatment medium, consisting of growth medium with $2 \%$ fetal bovine serum but without DMSO, 72 hours prior to treatment. Confluent (10 days postplating) and differentiated (after 72 hours of incubation with treatment medium) HepaRG cells were treated with vehicle $(0.1 \%$ DMSO or $0.1 \%$ ethanol) or a transcription factor activator for 48 hours at the concentrations indicated in the figure legends (treatments were renewed after 24 hours). The concentrations used for the various agonists were selected based on previous demonstrations that these concentrations produce optimal regulation of known target genes as well as some of the SULTs (Fang et al., 2007; Rondini et al., 2014; Barrett et al., 2016; Dubaisi et al., 2016).

Primary Human Fetal Hepatocyte Culture and Treatments. Deidentified tissues were obtained from Magee Women's Hospital (Pittsburgh, PA) and the University of Washington Department of Pediatrics, Division of Genetic Medicine, Laboratory of Developmental Biology (Seattle, WA) after obtaining written informed consent by a protocol approved by the Human Research Review Committee of the University of Pittsburgh (Honest Broker approval numbers HB015 and HB000836). Human fetal hepatocytes were isolated from fetal livers obtained after the termination of pregnancy performed at 12-22 weeks of gestation (Supplemental Table 1). Primary human fetal hepatocytes were isolated by digesting the tissue in Eagle's minimum essential medium (Lonza, Walkersville, MD) containing $0.5 \mathrm{mg} / \mathrm{ml}$ collagenase (Type XI; Sigma-Aldrich) on a laboratory shaker for 40 minutes. Viability was assessed by trypan blue exclusion and was routinely $>85 \%$. Hepatocytes were plated at a density of 130,000 cells $/ \mathrm{cm}^{2}$ on type I rat tail collagen-coated 12-well plates (Corning, Corning, NY). Cells were cultured overnight with Dulbecco's modified Eagle's medium (Thermo Fisher Scientific) containing $100 \mathrm{U} / \mathrm{ml}$ penicillin, $100 \mu \mathrm{g} / \mathrm{ml}$ streptomycin, $0.1 \mu \mathrm{M}$ insulin (Sigma-Aldrich), and 5\% bovine serum albumin (Thermo Fisher Scientific). Hepatocytes were then treated with vehicle $(0.1 \%$ DMSO or $0.1 \%$ ethanol) or a transcription factor activator for 48 hours, as indicated in the legends to Figs. 1 and 2 (treatments were renewed after 24 hours).

RNA Isolation and Analysis. Total RNA was isolated from HepaRG cells and freshly isolated and cultured human fetal hepatocytes using the PureLink RNA Mini Kit (Thermo Fisher Scientific). Samples of RNA $(1.5 \mu \mathrm{g})$ were

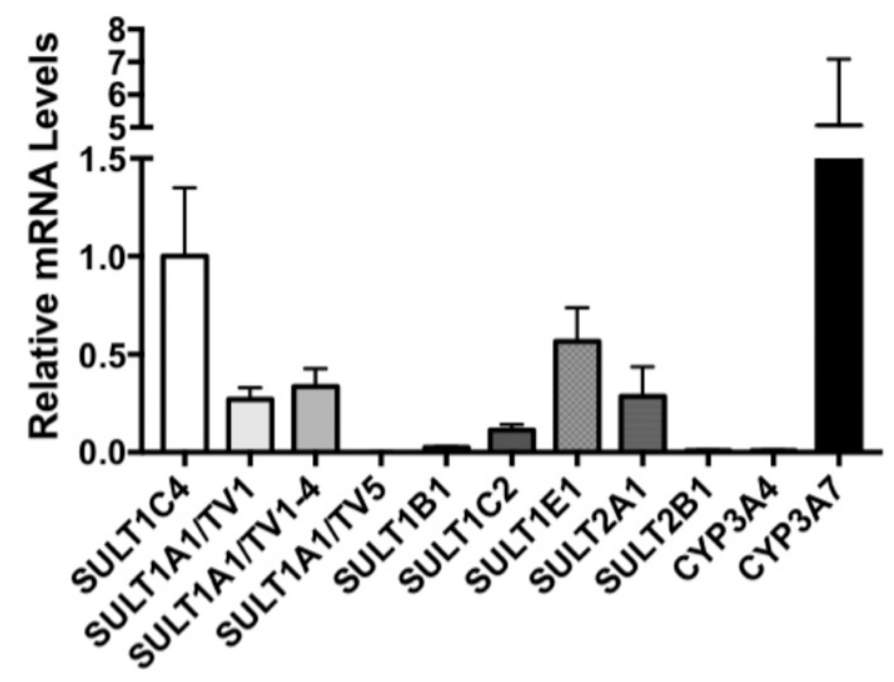

Fig. 1. SULT, CYP3A4, and CYP3A7 expression in primary cultured human fetal hepatocytes. Freshly isolated hepatocytes from five fetal livers were incubated in medium containing $0.1 \%$ DMSO for 48 hours, after which the cells were harvested and SULT, CYP3A4, CYP3A7, and GAPDH (used as a normalization gene) mRNA levels were measured using TaqMan Gene Expression Assays. Each bar represents the mean relative mRNA level \pm S.E.M. for the five independent experiments compared with SULT1C4, which had the highest expression of the SULTs. Relative CYP3A4 and CYP3A7 mRNA levels are shown for comparison. 

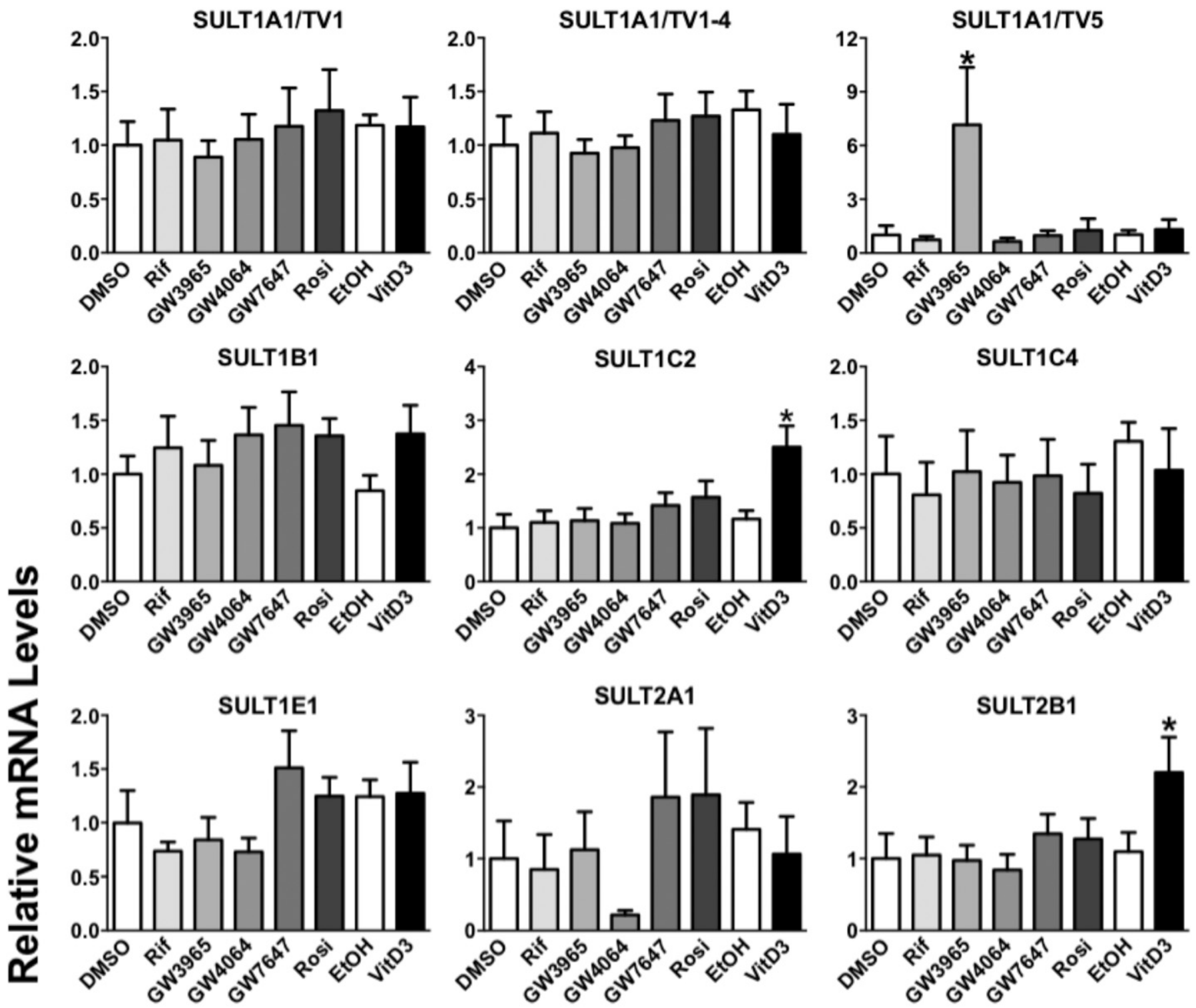

\section{SULT2A1}
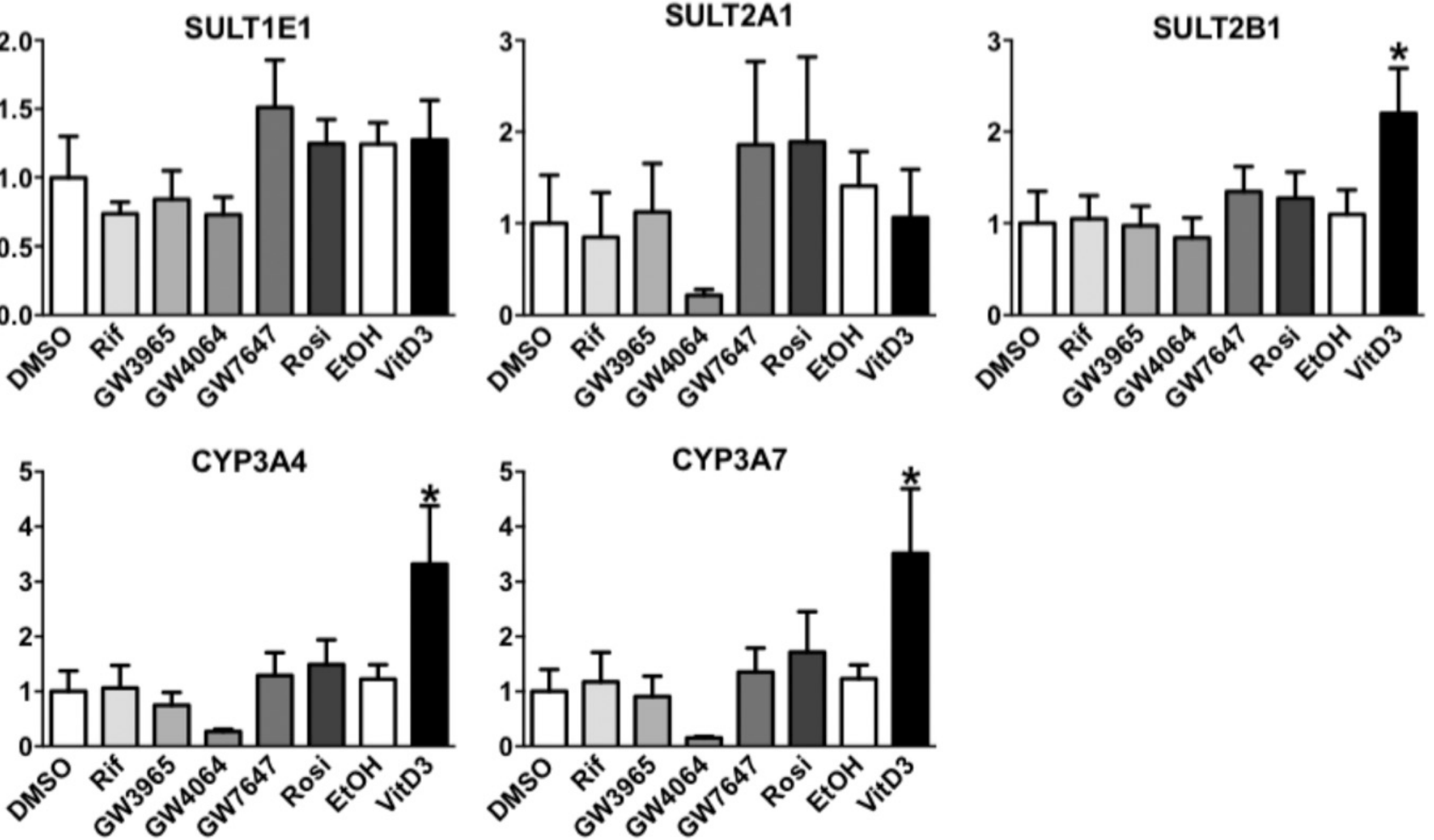

Fig. 2. Effects of nuclear receptor agonists on SULT, CYP3A4, and CYP3A7 expression in primary cultured human fetal hepatocytes. Freshly isolated hepatocytes from five fetal livers were incubated in medium containing $0.1 \%$ DMSO, $0.1 \%$ ethanol (EtOH), $10 \mu \mathrm{M}$ rifampicin (Rif), $10 \mu \mathrm{M}$ GW3965, $10 \mu \mathrm{M}$ GW4064, $10 \mu \mathrm{M}$ GW7647, $1 \mu \mathrm{M}$ rosiglitazone (Rosi), or $0.1 \mu \mathrm{M} \mathrm{VitD}$ for 48 hours, after which the cells were harvested and SULT, CYP3A4, CYP3A7, and GAPDH (used as a normalization gene) mRNA levels were measured. Each bar represents the mean relative mRNA level \pm S.E.M. compared with control $(0.1 \%$ ethanol for VitD $; 0.1 \%$ DMSO for other agonists) for the five independent experiments. *Significantly different from control, $P<0.05$.

reversed transcribed to cDNA using the High-Capacity cDNA Reverse Transcription Kit, according to the manufacturer instructions (Thermo Fisher Scientific). RNA levels were quantified using the TaqMan Gene Expression Assays (Thermo
Fisher Scientific) listed in Supplemental Table 2, $2 \mu 1$ of diluted cDNA (1:2), and a StepOnePlus Real-Time PCR System (Applied Biosystems, Foster City, CA). The assays were performed as described previously (Fang et al., 2007). 
Western Blot Analysis. HepaRG cells were plated into six-well plates at a density of 250,000 cells/well and harvested after 5, 9, 14, 19, 26, or 30 days for the preparation of whole-cell lysates, as previously described (Rondini et al., 2014). Protein concentrations were determined using the BCA Protein Assay Kit (Thermo Fisher Scientific). Proteins (20-30 $\mu \mathrm{g}$ ) were resolved on $12.5 \%$ SDSPAGE gels, transferred onto polyvinylidene difluoride membranes, and incubated for 1 hour with blocking buffer (2.5\% nonfat dry milk in Tris-buffered saline with Tween 20; Sigma-Aldrich). The membranes were then incubated overnight at $4^{\circ} \mathrm{C}$ with mouse monoclonal anti-SULT1C2 (clone OTI5A4; Origene, Rockville, MD) diluted 1:5000, anti-SULT1E1 (clone E-12; Santa Cruz Biotechnology, Dallas, TX) diluted 1:2000, or anti-SULT2A1 (clone OTI4D7; Origene) diluted 1:5000 followed by incubation with horseradish peroxidase-conjugated goat anti-mouse IgG (sc-2005; Santa Cruz Biotechnology) diluted 1:20,000 (for membranes probed with anti-SULT1E1 or anti-SULT2A1) or 1:25,000 (for membranes probed with anti-SULT1C2). Enhanced chemiluminescence and a FluorChem E detection system (ProteinSimple, San Jose, CA) were used to visualize the immunoreactive bands. The blots were then incubated in stripping buffer $(60 \mathrm{mM}$ Tris- $\mathrm{HCl}, 70 \mathrm{mM}$ sodium dodecyl sulfate, and $100 \mathrm{mM}$ $\beta$-mercaptoethanol) at $37^{\circ} \mathrm{C}$ to remove the antibodies and reprobed with $\beta$-actin antibody (clone AC15; Sigma-Aldrich) diluted 1:40,000 followed by horseradish peroxidase-conjugated goat anti-mouse IgG diluted 1:100,000. Band densities were quantified with ImageJ32 software (Schneider et al., 2012).

Statistical Analysis. All experiments, except where indicated in the figure legends, were repeated at least three times. Gene expression data are presented as the mean \pm S.E.M. (with three or more independent experiments) or range (with two independent experiments) relative to control. Statistical analyses were performed using Prism (version 6; GraphPad, La Jolla, CA). Data were analyzed using two-tailed unpaired $t$ tests or one- or two-way analysis of variance followed by Tukey's post hoc test, with $P<0.05$ considered to be significantly different.

\section{Results}

Expression and Regulation of SULTs in Primary Cultures of Human Fetal Hepatocytes. To study the regulation of SULTs in a model of human fetal liver, hepatocytes were isolated from five fetal livers and placed into primary culture, and the cultures were treated for 48 hours with a vehicle $(0.1 \%$ DMSO or $0.1 \%$ ethanol) or a panel of nuclear receptor activators. SULT mRNA levels were then measured, together with CYP3A7 and CYP3A4 for comparison, since these genes are well known to be predominantly expressed in fetal or adult liver, respectively. Since several SULT1A1 transcript variants (TVs) have been described (five confirmed mRNAs, National Center for Biotechnology Information SULT1A1 UniGene Hs.567342), we used three different TaqMan Gene Expression Assays to measure the following: 1) TV1 separately, since this variant is described as being most abundant; 2) TVs $1-4$ as a group, since these four variants likely use the same transcription start site; and 3) TV5 separately, since the transcription start site of this variant is distinct from that of TVs $1-4$ (i.e., more than $10 \mathrm{~kb}$ upstream). The mRNA levels measured in the DMSO-treated hepatocytes were considered as estimates of basal expression. As expected, CYP3A7 was highly expressed [as estimated by cycle threshold $\left(\mathrm{C}_{\mathrm{t}}\right)$ values] in the cultured fetal hepatocytes $\left(C_{t}=23.6\right)$, whereas CYP3A4 expression was minimal $\left(C_{t}=32.7\right)$ (Fig. 1). Of the SULTs, SULT1C4 was most highly expressed $\left(C_{t}=25.9\right)$, followed by SULT1E1 $\left(C_{t}=\right.$ 26.4), whereas SULT1A1 (TVs 1 and $1-4 ; C_{t}=28.2$ for both assays), SULT2A1 $\left(C_{t}=28.4\right)$, and SULT1C2 $\left(C_{t}=28.6\right)$ mRNA levels were somewhat lower but still readily detectable. SULT1A1 TV5 $\left(C_{t}=35.8\right)$, SULT1B1 $\left(C_{t}=30.7\right)$, SULT1C3 $\left(C_{t}=36.6\right)$, and SULT2B1 $\left(C_{t}=32.6\right)$ mRNA levels were low or barely detectable (Fig. 1). To evaluate the impact of placing freshly isolated human fetal hepatocytes into primary culture on SULT expression, the ratios of the mRNA levels in cultured relative to freshly isolated hepatocytes were calculated. Culturing the fetal hepatocytes reduced the expression of SULT1C2 (by 82\%), SULT1E1 (92\%), and SULT2A1 (94\%) but increased the expression of SULT1A1-TV5 (3-fold), SULT1B1 (14-fold), and SULT2B1 (6-fold)
(Supplemental Fig. 1). CYP3A7 and CYP3A4 expression was also decreased by primary culture, by approximately $91 \%$ and $38 \%$, respectively (Supplemental Fig. 1).

Treatment of the human fetal hepatocyte cultures with a panel of nuclear receptor activators produced several effects that were reproducibly seen across the five preparations. Treatment with the LXR agonist GW3965 $(10 \mu \mathrm{M})$ significantly increased the amount of SULT1A1 TV5 by an average of 7.2-fold (relative to DMSO-treated control) and treatment with the $\mathrm{VDR}$ agonist $\operatorname{VitD}_{3}(0.1 \mu \mathrm{M})$ significantly increased SULT1C2 and SULT2B1 mRNA content by an average of 2.2-fold and 2.0-fold, respectively (relative to ethanol-treated control). $\mathrm{VitD}_{3}$ treatment also increased CYP3A4 and CYP3A7 mRNA levels (by 2.7-fold and 2.9-fold, respectively). Although not significant, treatment with the $\operatorname{PPAR} \alpha$ agonist GW7647 $(10 \mu \mathrm{M})$ or PPAR $\gamma$ agonist rosiglitazone $(1 \mu \mathrm{M})$ increased the amount of SULT2A1 mRNA by 1.9-fold, whereas treatment with the FXR agonist GW4064 (10 $\mu \mathrm{M})$ decreased SULT2A1, CYP3A4, and CYP3A7 mRNA levels (by 78\%-85\%). None of the treatments produced clear changes in the levels of SULT1A1 TVs 1-4, SULT1B1, SULT1C4, or SULT1E1 mRNA (Fig. 2).

Temporal Expression of SULTs in HepaRG Cells. The approximately 1-month protocol for converting proliferating cultures of HepaRG cells into a mixed population of hepatocyte-like and cholangiocyte-like cells consists of growing the cells to confluency, maintaining them at confluency for several more days, and then incubating them in DMSOcontaining medium (Fig. 3A). To characterize the temporal expression of the SULTs in HepaRG cells as they progressed through the differentiation process, cells were plated and then harvested every 2-3 days for mRNA measurements (Fig. 3B). Again, CYP3A4 and CYP3A7 mRNA levels were measured for comparison. CYP3A4 expression was low in the proliferating cultures, increased somewhat during the confluent phase, and then further increased during the differentiation phase (Fig. 3B). By comparison, CYP3A7 expression was highest during the confluent phase and then decreased during the differentiation phase (Fig. 3B). The SULT2A1 expression profile was comparable to that for CYP3A4, with the highest expression occurring in the differentiated cells (Fig. 3B). Most of the other SULTs were expressed with patterns resembling that for CYP3A7 (i.e., SULT1B1, SULT1C2, SULT1C3, SULT1C4, and SULT1E1), where expression was highest in the confluent cultures and then reduced in the differentiated cultures (Fig. 3B). The expression of SULT1A1 transcripts and SULT2B1 did not vary markedly throughout the differentiation process (Fig. 3B). SULT1A1 TV 1-4 levels were abundant, whereas the expression of SULT1A1 TV5 and SULT2B1 was low.

The protein levels for three of the SULTs (SULT1C2, SULT1E1, and SULT2A1) showing the two major expression patterns that were observed at the mRNA level were also measured at several time points. Consistent with the patterns observed at the mRNA level, SULT1C2 and SULT1E1 protein content was highest in the confluent cells and then decreased after differentiation was induced by DMSO, whereas SULT2A1 protein reached its highest level in the differentiated HepaRG cells (Fig. 4).

Effects of Lipid- and Xenobiotic-Sensing Receptor Activators on SULT Expression in HepaRG Cells. To identify nuclear signaling pathways that regulate SULT expression in the HepaRG model of human liver cell differentiation, cells were treated for 48 hours with activators of the AhR and several lipid- and xenobiotic-sensing nuclear receptors that have been reported to regulate SULT expression in other human cell systems (Song et al., 2001; Fang et al., 2005, 2007; Jiang et al., 2005; Fu et al., 2011; Rondini et al., 2014; Barrett et al., 2016; Dubaisi et al., 2016). Both confluent and differentiated HepaRG cells were treated to consider the possibility that cells in the two stages could differ in their responses due to differences in their content of transcriptional machinery. However, 
(No DMSO)

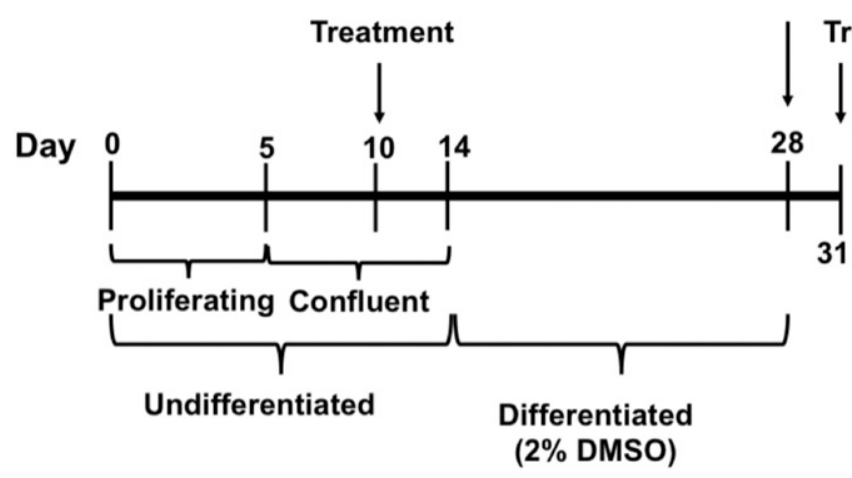

B
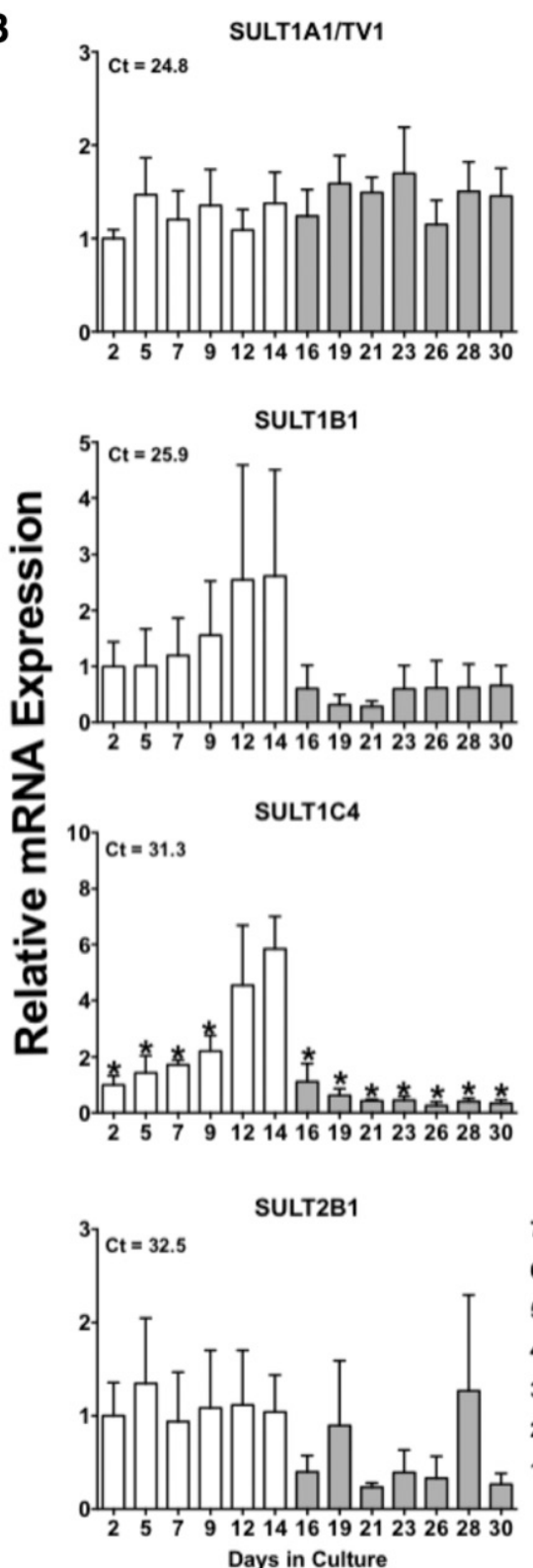
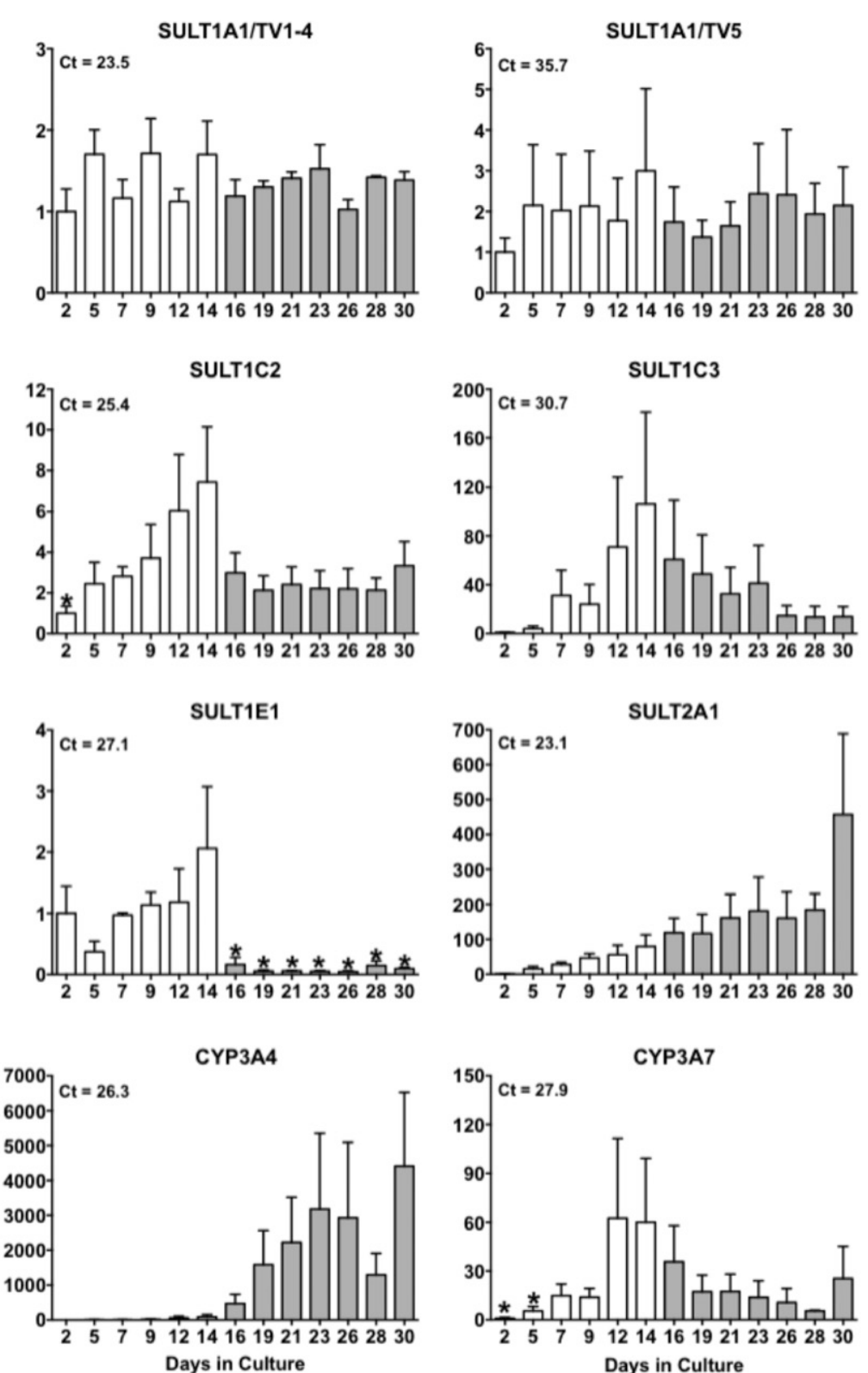

Fig. 3. Temporal expression of SULTs, CYP3A4, and CYP3A7 in HepaRG cells. (A) HepaRG differentiation protocol showing proliferating, confluent, and differentiated phases and the times when treatments were begun. (B) HepaRG cells were plated (day 0) and harvested on the indicated days for the measurement of mRNA levels. mRNA levels were normalized to the levels measured on day 2 (i.e., first harvest day). The data show the expression patterns of eight cytosolic SULTs as well as CYP3A4 and 

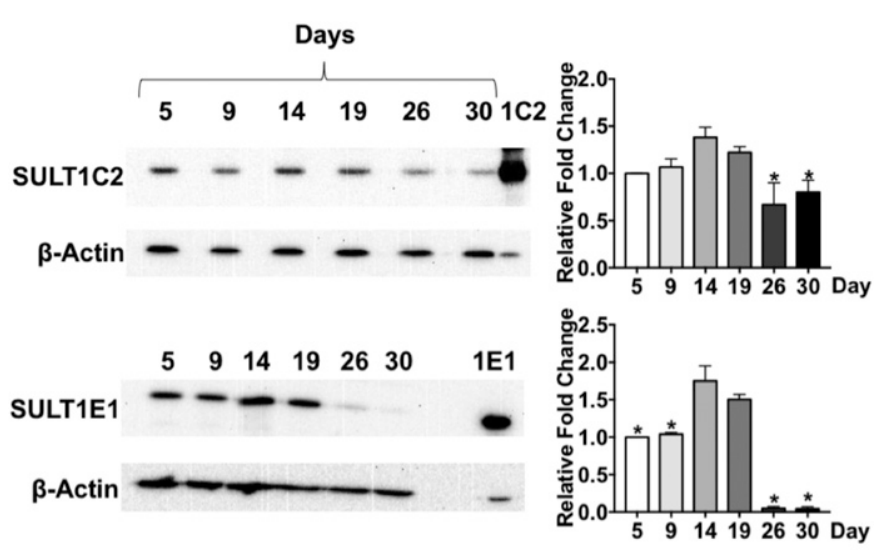

$\begin{array}{llllllll}5 & 9 & 14 & 19 & 26 & 30 & \mathrm{EV} & 2 \mathrm{~A} 1\end{array}$
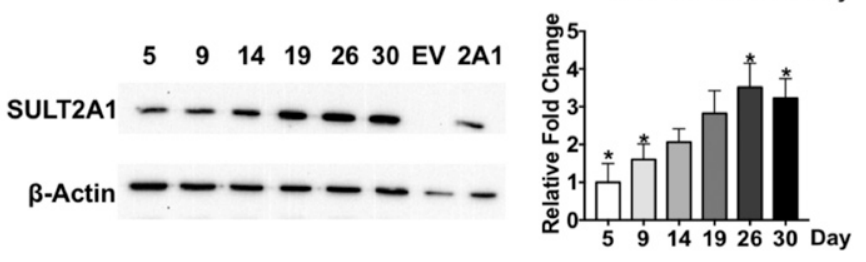

Fig. 4. SULT1C2, SULT1E1, and SULT2A1 immunoreactive protein levels in HepaRG cells harvested at different time points. HepaRG cells were plated (day 0 ) and harvested on the indicated days for the measurement of SULT1C2, SULT1E1, and SULT2A1 protein levels by Western blot analysis. $\beta$-actin was used as the loading control. The images shown are from one representative experiment. For each protein, the last lane contains a standard consisting of whole-cell lysate prepared from SULT cDNA-transfected human embryonic kidney 293 (HEK293) cells [empty vector (EV)-transfected HEK293 cells]. Band densities were quantified using ImageJ, and data are shown normalized to the protein levels measured at day 5 . Each bar represents the mean \pm S.E.M. from three independent experiments. *Significantly different from day $14(P<0.05)$.

the measurement of marker transcripts for the various nuclear signaling pathways indicated that all treatments activated their targeted transcription factors by comparable amounts in confluent and differentiated cells (Supplemental Figs. 2 and 3).

As shown in Fig. 5, treatment of confluent cells with the AhR agonist TCDD $(0.01 \mu \mathrm{M})$ significantly decreased the mRNA levels of all SULTs that were measured, except for SULT1C3, and decreases of at least $50 \%$ were seen for SULT1A1 TV5 (69\% decrease), SULT1B1 $(51 \%)$, SULT1C4 (77\%), SULT1E1 $(86 \%)$, and SULT2A1 $(86 \%)$. Treatment with the constitutive androstane receptor agonist CITCO $(1 \mu \mathrm{M})$ also significantly decreased the mRNA levels of several SULTs (SULT1B1, SULT1C3, SULT1C4, SULT1E1, and SULT2B1), although these decreases were generally modest and none exceeded $38 \%$. Treatment with the PXR agonist rifampicin $(10 \mu \mathrm{M})$ significantly increased SULT1C4 mRNA content (by 2.8-fold) and decreased the mRNA levels of SULT1B1 (63\% decrease), SULT1C3 (68\%), SULT1E1 (63\%), and SULT2A1 (62\%). GW3965 treatment (LXR agonist, $10 \mu \mathrm{M}$ ) significantly increased the amount of SULT1A1 TV5 (by 1.7-fold) and SULT1C4 mRNA (1.9-fold) and decreased the mRNA levels of SULT1C3, SULT1E1, SULT2A1, and SULT2B1, with the reduction of SULT1C3 mRNA being especially pronounced ( $>90 \%$ decrease). GW4064 treatment (FXR agonist, $1 \mu \mathrm{M}$ ) significantly decreased the expression of several SULTs (SULT1B1, SULT1C2, SULT1C3, SULT1C4, SULT1E1, SULT2A1), with the largest decreases seen for SULT1C3 (64\%) and SULT2A1 (68\%). Treatment with CDCA $(50 \mu \mathrm{M})$, another FXR agonist, produced effects that were comparable to those of GW4064, with the largest effects being the reduction of SULT1C3 (60\% decrease) and SULT2A1 (55\%) mRNA levels. GW7647 treatment (PPAR $\alpha$ agonist, $10 \mu \mathrm{M}$ ) significantly increased SULT1B1 mRNA content, although the increase was only 1.2-fold, and decreased SULT1A1 (only with the assay measuring TV1-4), SULT1C2, SULT1C3, and SULT2B1 mRNA levels, with the largest reduction seen for SULT1C3 $(81 \%)$. The PPAR $\gamma$ agonist rosiglitazone $(10 \mu \mathrm{M})$ had little effect on SULT expression, other than to decrease SULT1C3 mRNA content (72\% decrease). Treatment with $\mathrm{VitD}_{3}$ (VDR agonist, $0.1 \mu \mathrm{M}$ ) significantly increased the amounts of SULT1C2, SULT1C4, and SULT2B1 mRNA by 1.4-fold to 1.8-fold and decreased SULT1A1 (only with the assay measuring TV1), SULT1B1, SULT1C3, SULT1E1, and SULT2A1 mRNA levels, with the largest reduction seen for SULT1C3 (68\% decrease).

Figure 6 shows the effects of the treatments on SULT expression in differentiated HepaRG cells. Many of the effects were comparable to those seen in the confluent cultures, including 1) TCDD treatment decreased the expression of most SULTs; 2) CITCO treatment had relatively little effect on SULT expression; 3) rifampicin treatment significantly increased SULT1C4 mRNA content (by 6.3-fold) and decreased SULT1B1, SULT1C3, and SULT2A1 expression; 4) GW3965 treatment significantly increased SULT1A1 TV5 and SULT1C4 mRNA levels and markedly reduced (by $>90 \%$ ) SULT1C3 mRNA content, and levels of SULT2A1 and SULT2B1mRNA were also decreased; 5) GW4064 and CDCA treatments significantly decreased the mRNA levels of several SULTs, including SULT1C2, SULT1C3, SULT1E1, and SULT2A1; 6) GW7647 treatment modestly but significantly increased SULT1B1 mRNA content and decreased the amount of SULT1C3 mRNA; 7) rosiglitazone treatment decreased SULT1C3 expression; and 8) VitD3 treatment significantly increased SULT1C2 and SULT2B1 mRNA levels (SULT1C4 mRNA content also increased $\sim 2$-fold, although this effect was not significant in the differentiated cells) and decreased SULT1A1 (TV1), SULT1B1, SULT1C3, and SULT2A1 mRNA levels. Differences that were noted between the differentiated and confluent HepaRG cells were 1) TCDD treatment significantly decreased SULT1C2 mRNA content only in confluent cells and increased SULT1C3 mRNA only in differentiated cells; 2) rifampicin treatment significantly decreased SULT1E1 expression only in confluent cells and reduced SULT1A1 (TV1-4) but induced SULT2B1 in differentiated cells; 3) GW3965 treatment decreased the expression of SULT1A1 (TV1-4) by almost $50 \%$ only in differentiated cells; and 4) VitD3 treatment significantly decreased SULT1E1 expression only in confluent cells.

\section{Discussion}

Xenobiotic-metabolizing enzymes exhibit distinct patterns of developmental expression (Hines, 2008), and the particular combination of enzymes that is expressed at each life stage is a major determinant of the risk for development of an adverse response to a particular chemical exposure. For example, the gastroprokinetic drug cisapride was once prescribed to treat gastroesophageal reflux and other gastrointestinal disorders in neonates and infants. However, due to low CYP3A4 activity, cisapride treatment of neonates was associated with significant adverse effects on heart rhythm (Kearns et al., 2003).

SULTs are among the most highly expressed conjugating enzymes in fetal tissues (Coughtrie, 2015). In a concurrent study, we have expanded

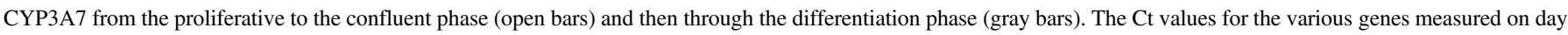

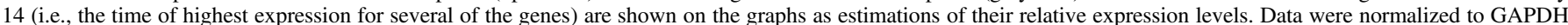
and are shown as the mean \pm S.E.M. from three independent experiments. $*$ Significantly different from day $14 \mathrm{mRNA}$ level, $P<0.05$. 

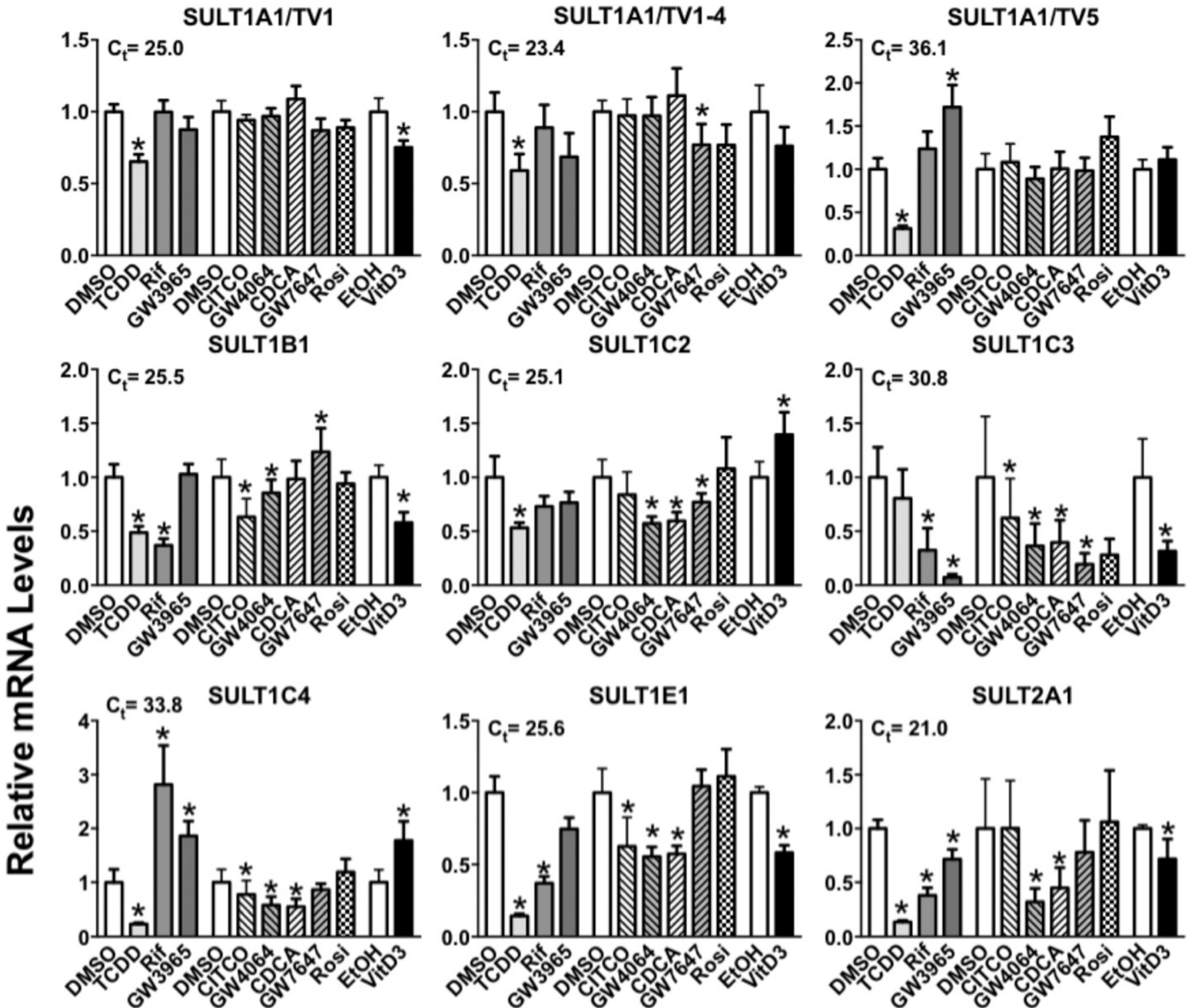

SULT1E1
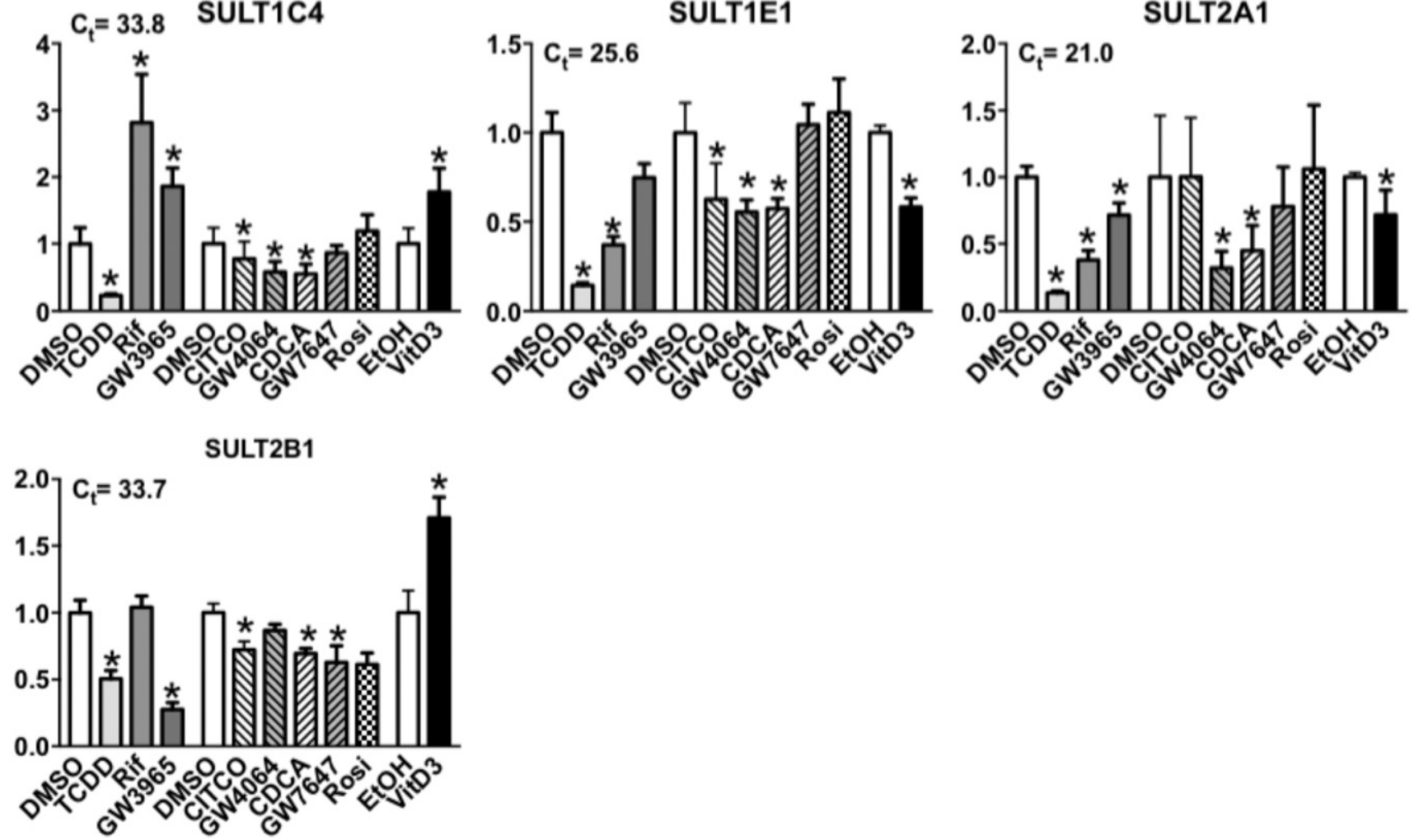

Fig. 5. Effects of lipid- and xenobiotic-sensing receptor activators on SULT mRNA levels in confluent HepaRG cells. Ten days after plating, confluent HepaRG cells were

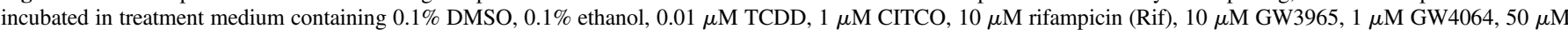
CDCA, $10 \mu \mathrm{M}$ GW7647, $10 \mu \mathrm{M}$ rosiglitazone (Rosi), or $0.1 \mu \mathrm{M}$ VitD 3 for 48 hours, after which cells were harvested and SULT and TATA-box binding protein (used as normalization gene) mRNA levels were measured. Each bar represents the mean relative mRNA level \pm range (for rosiglitazone treatment only) or S.E.M. compared with control ( $0.1 \%$ ethanol for VitD3; $0.1 \%$ DMSO for all other agonists) for two (for rosiglitazone) or three independent experiments. *Significantly different from control, $P<0.05 . \mathrm{C}_{\mathrm{t}}$ values for the various genes determined in DMSO-treated confluent HepaRG cells (from three independent experiments) as estimations of their relative expression levels. 

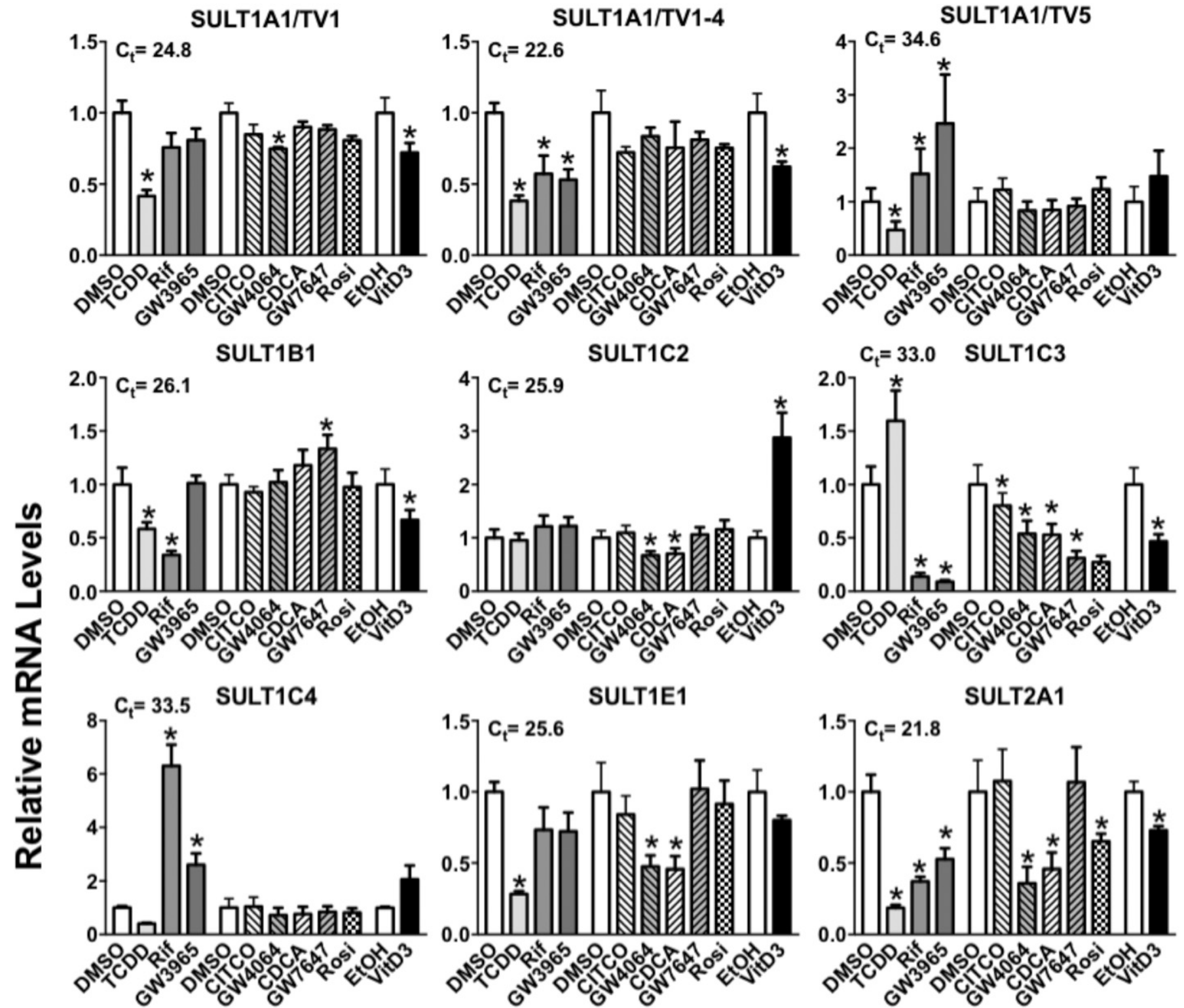

焉

SULT2B1

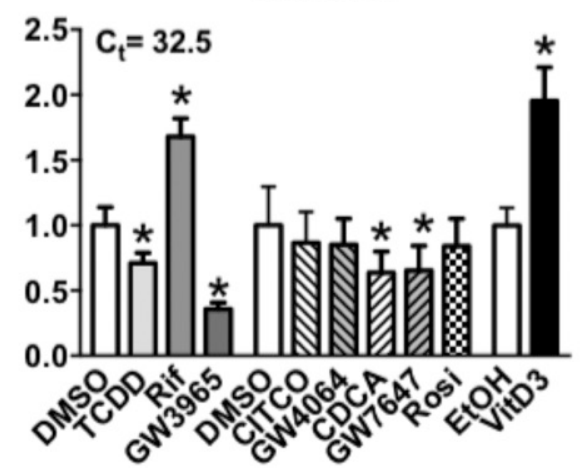

Fig. 6. Effects of lipid- and xenobiotic-sensing receptor activators on SULT mRNA levels in differentiated HepaRG cells. Four weeks after plating, differentiated HepaRG cells were incubated with treatment medium alone for 72 hours and then treatment medium containing $0.1 \%$ DMSO, $0.1 \%$ ethanol, $0.01 \mu \mathrm{M}$ TCDD, $1 \mu \mathrm{M} \mathrm{CITCO}, 10 \mu \mathrm{M}$ rifampicin (Rif), $10 \mu \mathrm{M}$ GW3965, $1 \mu \mathrm{M} \mathrm{GW} 4064,50 \mu \mathrm{M} \mathrm{CDCA}, 10 \mu \mathrm{M}$ GW7647, $10 \mu \mathrm{M}$ rosiglitazone (Rosi), or $0.1 \mu \mathrm{M}$ VitD $\mathrm{D}_{3}$ for 48 hours, after which cells were harvested and SULT and TATA-box binding protein (used as a normalization gene) mRNA levels were measured. Each bar represents the mean relative mRNA level \pm S.E.M. relative to control ( $0.1 \%$ ethanol for $\mathrm{VitD}_{3} ; 0.1 \%$ DMSO for all other agonists) from three independent experiments (except for SULT1A1/TV1 and SULT1A1TV1-4 for the CITCO, GW4064, CDCA, GW7647, and Rosi treatment groups, where each bar represents the mean \pm range from two independent experiments). *Significantly different from control, $P<0.05$. $\mathrm{C}_{\mathrm{t}}$ values for the various genes determined in DMSO-treated differentiated HepaRG cells (from three independent experiments) as estimations of their relative expression levels. 
our previous characterization of the developmental expression of SULT1A1, SULT1E1, and SULT2A1 in human liver (Duanmu et al., 2006) by defining the developmental expression of multiple SULTs at the mRNA and protein levels (S. Dubaisi, J. A. Caruso, R. Gaedigk, C. A. Vyhlidal, D. G. McCarver, R. N. Hines, T. A. Kocarek, and M. Runge-Morris, manuscript in preparation). These data show that SULT1A1, SULT1C2, SULT1E1, and SULT2A1 mRNA and protein are substantially expressed in prenatal liver, whereas SULT1C4 is substantially expressed only at the mRNA level. SULT1C4 was recently shown to metabolize estrogenic compounds, including estradiol and environmental estrogens (Guidry et al., 2017). Although hepatic expression of the SULT1C genes and SULT1E1 decreases during the transition from fetal to adult life, SULT1A1 expression stays relatively constant whereas SULT2A1 expression increases.

There is currently no published information about SULT expression or regulation in primary cultured human fetal hepatocytes. We show that the profile of SULT expression in freshly isolated fetal hepatocytes is comparable to that observed in the above-described study of liver specimens from tissue banks, in that SULT1A1, SULT1C2, SULT1C4, SULT1E1, and SULT2A1 are the most highly expressed SULTs. Placement of fetal hepatocytes into primary culture decreased the expression of several SULTs. A notable exception was SULT1B1, which is reported to be the third most highly expressed SULT in adult human liver (Riches et al., 2009). SULT1B1 mRNA content increased 14-fold after the fetal hepatocytes were placed into culture, implying a difference in the mechanisms controlling basal expression of SULT1B1 relative to other SULTs.

To identify mechanisms that regulate SULT expression in human fetal hepatocytes, primary cultures were treated with several activators of lipid- and xenobiotic-sensing receptors. Several significant effects and nonsignificant trends were observed, and are discussed in the context of previous findings. VDR activation significantly increased SULT1C2 as well as CYP3A7 and CYP3A4 mRNA levels. Although liver is not a classic $\mathrm{VitD}_{3}$-responsive organ, VDR is expressed in liver (Berger et al., 1988), and its activation has been shown to increase expression of several cytochrome P450 family members, including CYP3A4, in primary cultured adult human hepatocytes (Drocourt et al., 2002). We recently reported that VDR activation increases SULT1C2 expression in LS180 colorectal adenocarcinoma cells (Rondini et al., 2014; Barrett et al., 2016). Also, the treatment of fetal hepatocyte cultures with an agonist of PPAR $\alpha$ (GW7647) or PPAR $\gamma$ (rosiglitazone) increased the expression of SULT2A1 by approximately 2-fold, which is consistent with our previous report (Fang et al., 2005) that treatment with the PPAR $\alpha$ agonist ciprofibrate produced approximately that level of SULT2A1 induction in primary cultured adult human hepatocytes. In addition, treatment with the FXR agonist GW4064 suppressed SULT2A1 in the cultured fetal hepatocytes, which is consistent with the FXR-mediated suppression of SULT2A1 that has been previously reported in mouse liver and HepG2 human hepatoma cells (Miyata et al., 2006).

A novel finding in the cultured fetal hepatocytes was that treatment with the LXR agonist GW3965 significantly increased the expression of SULT1A1 TV5. TV5 is reported to be a rare variant that contains a distinct $5^{\prime}$-untranslated region and lacks part of the $5^{\prime}$-coding region, and its transcription start site is located more than $10 \mathrm{~kb}$ upstream from that of other SULT1A1 transcripts (National Center for Biotechnology Information data for NM_177536 and SULT1A1 gene). The distinct location of the TV5 promoter provides a plausible explanation for the unique regulation of this SULT1A1 variant by LXR, which prompts speculation that SULT1A1 TV5 could play a role in sterol metabolism.

Most studies using HepaRG cells have used differentiated cells as a model to complement the use of primary cultured human hepatocytes (Josse et al., 2008; Lubberstedt et al., 2011; Gerets et al., 2012; Klein et al., 2015). However, few studies have evaluated the changes in xenobiotic-metabolizing enzyme expression that occur as HepaRG cells pass through the stages of the differentiation process (Aninat et al., 2006; Hart et al., 2010; Ceelen et al., 2011; Tsuji et al., 2014; Bucher et al., 2017), and no studies have determined expression of the individual SULTs. We found that SULT1B1, SULT1C2, SULT1C3, SULT1C4, and SULT1E1 mRNA levels were highest in confluent HepaRG cells, whereas SULT2A1 RNA levels increased throughout the differentiation process. The temporal trends of gene expression, whereby the SULTs that are preferentially expressed in fetal livers and hepatocytes are also preferentially expressed in confluent HepaRG cells, whereas the SULT that is preferentially expressed in adult liver and hepatocytes is expressed at the highest level in differentiated HepaRG cells, provide additional support to the suggestion that HepaRG cells at these stages of the differentiation protocol can serve as experimental models of human hepatocyte development.

We also evaluated the effects of activators of lipid- and xenobioticsensing transcription factors on SULT expression in HepaRG cells, comparing the effects at the confluent and differentiated stages. More activator-mediated changes in SULT expression were observed in the HepaRG cells than in the primary cultured fetal hepatocytes. However, although there were marked temporal changes in SULT expression as the cells underwent differentiation (noted above), most of the transcription factor activator-mediated changes were comparable in the confluent and differentiated HepaRG cells, indicating that the evaluated nuclear signaling pathways were already functional in the confluent cells. As seen in the human fetal hepatocytes, GW3965 and $\mathrm{VitD}_{3}$ treatment increased SULT1A1 TV5 and SULT1C2 mRNA levels, respectively, whereas FXR agonists GW4064 and CDCA suppressed SULT2A1 expression. Treatment with GW4064 or CDCA also significantly suppressed SULT1E1 expression in confluent HepaRG cells, but GW4064 produced only a slight reduction of SULT1E1 mRNA content in primary cultured fetal hepatocytes. FXR was recently reported to suppress SULT1E1 expression in HepG2 cells by inhibiting the binding of PPAR $\gamma$ coactivator $1 \alpha$ to hepatocyte nuclear factor $4 \alpha$ (Wang et al., 2017).

The effects of the PXR agonist rifampicin differed between HepaRG cells and fetal hepatocytes. Rifampicin treatment increased SULT1C4 expression and suppressed SULT1E1 and SULT2A1 expression in HepaRG cells but not in the fetal hepatocytes. We previously reported that rifampicin-mediated PXR activation suppresses hepatic SULT2A1 expression (Fang et al., 2007), whereas the mechanism of PXR-mediated suppression of SULT1E1 was described by Kodama et al. (2011). Rifampicin treatment also did not increase CYP3A4 or CYP3A7 expression in the cultured fetal hepatocytes, suggesting that PXR was not functional in these cells. Our findings agree with a previous report by Maruyama et al. (2007), who evaluated cytochrome P450 expression in human fetal liver cells prepared from a pool of six normal human fetal livers (average 13 weeks of gestation). These cells expressed CYP3A4 and CYP3A7, and treatment with dexamethasone, which is an effective agonist of rodent but not human PXR, significantly increased CYP3A4 and CYP3A7 mRNA levels (Maruyama et al., 2007). However, the treatment of the fetal liver cells with rifampicin did not increase CYP3A4 or CYP3A7 expression, and PXR mRNA was not detected by reversetranscription polymerase chain reaction (Maruyama et al., 2007). Vyhlidal et al. (2006) have also reported that PXR expression is lower in fetal relative to postnatal livers. These findings demonstrate that although confluent HepaRG cells model some aspects of the fetal hepatocyte, the presence of PXR signaling in confluent HepaRG cells and its absence in fetal hepatocytes indicate that confluent HepaRG cells do not fully recapitulate all aspects of the fetal hepatocyte, at least at the culture and gestation times that were evaluated. 
To date, SULT1C3 mRNA has been detected only in human intestinal tissue and cells (Duniec-Dmuchowski et al., 2014). In this study, we detected SULT1C3 mRNA in HepaRG cells, mainly at the confluent stage where the mRNA levels were approximately the same as those for SULT1C4. SULT1C3 expression was significantly reduced in the HepaRG cells by most of the treatments that were evaluated, with almost complete suppression by the LXR agonist GW3965. It seems possible that these suppressive effects contribute to the lack of SULT1C3 expression that has generally been seen in human liver samples.

TCDD treatment was also found to suppress the expression of most SULTs in HepaRG cells. This finding is consistent with the suppressive effects of AhR agonist treatments on SULT expression that we have previously reported in rat hepatocytes (Runge-Morris, 1998) and MCF10A human breast epithelial cells (Fu et al., 2011).

Several SULTs are expressed in human fetal liver, indicating that these enzymes play important roles during early life, likely in the metabolism of both endogenous and xenobiotic substrates. This study represents the first effort to define patterns of SULT expression in cell culture models of human fetal liver and liver cell differentiation and to identify signaling pathways that regulate SULT transcription in these cells. Further studies are warranted to understand the regulation of the SULTs during human development.

\section{Acknowledgments}

We thank the developers of the HepaRG cell line at the Institut National de la Santé et de la Recherche Médicale (INSERM) for providing us with the cell line. The TCDD that was used in this project was provided by the National Cancer Institute Chemical Carcinogen Reference Standards Repository operated under contract N02-CB-66600 by Midwest Research Institute.

\section{Authorship Contributions}

Participated in research design: Dubaisi, Barrett, Soto-Gutierrez, Kocarek, and Runge-Morris.

Conducted experiments: Dubaisi, Barrett, Fang, and Guzman-Lepe.

Performed data analysis: Dubaisi, Barrett, and Kocarek.

Wrote or contributed to the writing of the manuscript: Dubaisi, SotoGutierrez, Kocarek, and Runge-Morris.

\section{References}

Allali-Hassani A, Pan PW, Dombrovski L, Najmanovich R, Tempel W, Dong A, Loppnau P, Martin F, Thornton J, Edwards AM, et al. (2007) Structural and chemical profiling of the human cytosolic sulfotransferases [published correction appears in PLoS Biol (2007) 5:e165]. PLoS Biol 5:e97.

Aninat C, Piton A, Glaise D, Le Charpentier T, Langouët S, Morel F, Guguen-Guillouzo C, and Guillouzo A (2006) Expression of cytochromes P450, conjugating enzymes and nuclear receptors in human hepatoma HepaRG cells. Drug Metab Dispos 34:75-83.

Barker EV, Hume R, Hallas A, and Coughtrie WH (1994) Dehydroepiandrosterone sulfotransferase in the developing human fetus: quantitative biochemical and immunological characterization of the hepatic, renal, and adrenal enzymes. Endocrinology 134:982-989.

Barrett KG, Fang H, Kocarek TA, and Runge-Morris M (2016) Transcriptional regulation of cytosolic sulfotransferase $1 \mathrm{C} 2$ by vitamin D receptor in LS180 human colorectal adenocarcinoma cells. Drug Metab Dispos 44:1431-1434

Berger U, Wilson P, McClelland RA, Colston K, Haussler MR, Pike JW, and Coombes RC (1988) Immunocytochemical detection of 1,25-dihydroxyvitamin D receptors in normal human tissues. J Clin Endocrinol Metab 67:607-613.

Bucher S, Jalili P, Le Guillou D, Begriche K, Rondel K, Martinais S, Zalko D, Corlu A, Robin MA, and Fromenty B (2017) Bisphenol a induces steatosis in HepaRG cells using a model of perinatal exposure. Environ Toxicol 32:1024-1036.

Ceelen L, De Spiegelaere W, David M, De Craene J, Vinken M, Vanhaecke T, and Rogiers V (2011) Critical selection of reliable reference genes for gene expression study in the HepaRG cell line. Biochem Pharmacol 81:1255-1261.

Coughtrie MW (2015) Ontogeny of human conjugating enzymes. Drug Metab Lett 9:99-108.

Drocourt L, Ourlin JC, Pascussi JM, Maurel P, and Vilarem MJ (2002) Expression of CYP3A4, CYP2B6, and CYP2C9 is regulated by the vitamin D receptor pathway in primary human hepatocytes. J Biol Chem 277:25125-25132.

Duanmu Z, Weckle A, Koukouritaki SB, Hines RN, Falany JL, Falany CN, Kocarek TA, and Runge-Morris M (2006) Developmental expression of aryl, estrogen, and hydroxysteroid sulfotransferases in pre- and postnatal human liver. J Pharmacol Exp Ther 316:1310-1317.

Dubaisi S, Fang H, Kocarek TA, and Runge-Morris M (2016) Transcriptional regulation of human cytosolic sulfotransferase 1C3 by peroxisome proliferator-activated receptor $\gamma$ in LS180 human colorectal adenocarcinoma cells. Mol Pharmacol 90:562-569.

Duniec-Dmuchowski Z, Rondini EA, Tibbs ZE, Falany CN, Runge-Morris M, and Kocarek TA (2014) Expression of the orphan cytosolic sulfotransferase SULT1C3 in human intestine: characterization of the transcript variant and implications for function. Drug Metab Dispos 42: $352-360$.

Echchgadda I, Song CS, Oh TS, Cho SH, Rivera OJ, and Chatterjee B (2004a) Gene regulation for the senescence marker protein DHEA-sulfotransferase by the xenobiotic-activated nuclear pregnane X receptor (PXR). Mech Ageing Dev 125:733-745.

Echchgadda I, Song CS, Roy AK, and Chatterjee B (2004b) Dehydroepiandrosterone sulfotransferase is a target for transcriptional induction by the vitamin D receptor. Mol Pharmacol $\mathbf{6 5}$ 720-729.

Falany CN, Krasnykh V, and Falany JL (1995) Bacterial expression and characterization of a cDNA for human liver estrogen sulfotransferase. J Steroid Biochem Mol Biol 52:529-539.

Fang HL, Strom SC, Cai H, Falany CN, Kocarek TA, and Runge-Morris M (2005) Regulation of human hepatic hydroxysteroid sulfotransferase gene expression by the peroxisome proliferatoractivated receptor alpha transcription factor. Mol Pharmacol 67:1257-1267.

Fang HL, Strom SC, Ellis E, Duanmu Z, Fu J, Duniec-Dmuchowski Z, Falany CN, Falany JL, Kocarek TA, and Runge-Morris M (2007) Positive and negative regulation of human hepatic hydroxysteroid sulfotransferase (SULT2A1) gene transcription by rifampicin: roles of hepatocyte nuclear factor 4alpha and pregnane X receptor. J Pharmacol Exp Ther 323:586-598.

Forbes KJ, Hagen M, Glatt H, Hume R, and Coughtrie MW (1995) Human fetal adrena hydroxysteroid sulphotransferase: cDNA cloning, stable expression in V79 cells and functional characterisation of the expressed enzyme. Mol Cell Endocrinol 112:53-60.

Fu J, Fang H, Paulsen M, Ljungman M, Kocarek TA, and Runge-Morris M (2011) Regulation of estrogen sulfotransferase expression by confluence of MCF10A breast epithelial cells: role of the aryl hydrocarbon receptor. J Pharmacol Exp Ther 339:597-606.

Gerets HH, Tilmant K, Gerin B, Chanteux H, Depelchin BO, Dhalluin S, and Atienzar FA (2012) Characterization of primary human hepatocytes, HepG2 cells, and HepaRG cells at the mRNA level and CYP activity in response to inducers and their predictivity for the detection of human hepatotoxins. Cell Biol Toxicol 28:69-87.

Guidry AL, Tibbs ZE, Runge-Morris M, and Falany CN (2017) Expression, purification and characterization of human cytosolic sulfotransferase (SULT) 1C4. Horm Mol Biol Clin Investig 29:27-36.

Hart SN, Li Y, Nakamoto K, Subileau EA, Steen D, and Zhong XB (2010) A comparison of whole genome gene expression profiles of HepaRG cells and HepG2 cells to primary human hepatocytes and human liver tissues. Drug Metab Dispos 38:988-994.

Her C, Kaur GP, Athwal RS, and Weinshilboum RM (1997) Human sulfotransferase SULT1C1: cDNA cloning, tissue-specific expression, and chromosomal localization. Genomics 41: 467-470.

Higashi Y, Fuda H, Yanai H, Lee Y, Fukushige T, Kanzaki T, and Strott CA (2004) Expression of cholesterol sulfotransferase (SULT2B1b) in human skin and primary cultures of human epidermal keratinocytes. J Invest Dermatol 122:1207-1213.

Hines RN (2007) Ontogeny of human hepatic cytochromes P450. J Biochem Mol Toxicol 21: $169-175$.

Hines RN (2008) The ontogeny of drug metabolism enzymes and implications for adverse drug events. Pharmacol Ther 118:250-267.

Hirshey SJ and Falany CN (1990) Purification and characterization of rat liver minoxidil sulphotransferase. Biochem J 270:721-728.

Hoekstra R, Nibourg GA, van der Hoeven TV, Plomer G, Seppen J, Ackermans MT, Camus S, Kulik W, van Gulik TM, Elferink RP, et al. (2013) Phase 1 and phase 2 drug metabolism and bile acid production of HepaRG cells in a bioartificial liver in absence of dimethyl sulfoxide. Drug Metab Dispos 41:562-567.

Jiang YJ, Kim P, Elias PM, and Feingold KR (2005) LXR and PPAR activators stimulate cholesterol sulfotransferase type 2 isoform $1 \mathrm{~b}$ in human keratinocytes. J Lipid Res 46:2657-2666. Johnson GA, Barsuhn KJ, and McCall JM (1983) Minoxidil sulfate, a metabolite of minoxidil. Drug Metab Dispos 11:507-508.

Jossé R, Aninat C, Glaise D, Dumont J, Fessard V, Morel F, Poul JM, Guguen-Guillouzo C, and Guillouzo A (2008) Long-term functional stability of human HepaRG hepatocytes and use for chronic toxicity and genotoxicity studies. Drug Metab Dispos 36:1111-1118.

Kearns GL, Robinson PK, Wilson JT, Wilson-Costello D, Knight GR, Ward RM, and van den Anker JN; Pediatric Pharmacology Research Unit Network (2003) Cisapride disposition in neonates and infants: in vivo reflection of cytochrome P450 3A4 ontogeny. Clin Pharmacol Ther 74:312-325

Klein M, Thomas M, Hofmann U, Seehofer D, Damm G, and Zanger UM (2015) A systematic comparison of the impact of inflammatory signaling on absorption, distribution, metabolism, and excretion gene expression and activity in primary human hepatocytes and HepaRG cells. Drug Metab Dispos 43:273-283.

Kodama S, Hosseinpour F, Goldstein JA, and Negishi M (2011) Liganded pregnane X receptor represses the human sulfotransferase SULT1E1 promoter through disrupting its chromatin structure. Nucleic Acids Res 39:8392-8403.

Li X, Clemens DL, and Anderson RJ (2000) Sulfation of iodothyronines by human sulfotransferase 1C1 (SULT1C1)*. Biochem Pharmacol 60:1713-1716.

Lübberstedt M, Müller-Vieira U, Mayer M, Biemel KM, Knöspel F, Knobeloch D, Nüssler AK, Gerlach JC, and Zeilinger K (2011) HepaRG human hepatic cell line utility as a surrogate for primary human hepatocytes in drug metabolism assessment in vitro. J Pharmacol Toxicol Methods 63:59-68.

Maruyama M, Matsunaga T, Harada E, and Ohmori S (2007) Comparison of basal gene expression and induction of CYP3As in HepG2 and human fetal liver cells. Biol Pharm Bull 30:2091-2097.

Miki Y, Nakata T, Suzuki T, Darnel AD, Moriya T, Kaneko C, Hidaka K, Shiotsu Y, Kusaka H, and Sasano H (2002) Systemic distribution of steroid sulfatase and estrogen sulfotransferase in human adult and fetal tissues. J Clin Endocrinol Metab 87:5760-5768.

Miyata M, Matsuda Y, Tsuchiya H, Kitada H, Akase T, Shimada M, Nagata K, Gonzalez FJ, and Yamazoe Y (2006) Chenodeoxycholic acid-mediated activation of the farnesoid X receptor negatively regulates hydroxysteroid sulfotransferase. Drug Metab Pharmacokinet 21:315-323. Nunn AD, Scopigno T, Pediconi N, Levrero M, Hagman H, Kiskis J, and Enejder A (2016) The histone deacetylase inhibiting drug Entinostat induces lipid accumulation in differentiated HepaRG cells [published correction appears in Sci Rep (2016) 6:37204]. Sci Rep 6:28025.

Pai TG, Sugahara T, Suiko M, Sakakibara Y, Xu F, and Liu MC (2002) Differential xenoestrogensulfating activities of the human cytosolic sulfotransferases: molecular cloning, expression, and purification of human SULT2B1a and SULT2B1b sulfotransferases. Biochim Biophys Acta 1573: $165-170$.

Parent R, Marion MJ, Furio L, Trépo C, and Petit MA (2004) Origin and characterization of a human bipotent liver progenitor cell line. Gastroenterology 126:1147-1156. 
Riches Z, Stanley EL, Bloomer JC, and Coughtrie MW (2009) Quantitative evaluation of the expression and activity of five major sulfotransferases (SULTs) in human tissues: the SULT "pie". Drug Metab Dispos 37:2255-2261.

Rodrigues RM, Govaere O, Roskams T, Vanhaecke T, Rogiers V, and De Kock J (2016) Gene expression data from acetaminophen-induced toxicity in human hepatic in vitro systems and clinical liver samples. Data Brief 7:1052-1057.

Rondini EA, Fang H, Runge-Morris M, and Kocarek TA (2014) Regulation of human cytosolic sulfotransferases 1C2 and 1C3 by nuclear signaling pathways in LS180 colorectal adenocarcinoma cells. Drug Metab Dispos 42:361-368.

Runge-Morris M (1998) Regulation of sulfotransferase gene expression by glucocorticoid hormones and xenobiotics in primary rat hepatocyte culture. Chem Biol Interact 109:315-327.

Sadler NC, Nandhikonda P, Webb-Robertson BJ, Ansong C, Anderson LN, Smith JN, Corley RA, and Wright AT (2016) Hepatic cytochrome P450 activity, abundance, and expression throughout human development. Drug Metab Dispos 44:984-991.

Sakakibara Y, Yanagisawa K, Katafuchi J, Ringer DP, Takami Y, Nakayama T, Suiko M, and Liu MC (1998) Molecular cloning, expression, and characterization of novel human SULT1C sulfotransferase that catalyze the sulfonation of N-hydroxy-2-acetylaminofluorene. J Biol Chem 273:33929-33935.

Sayyed K, Vee ML, Abdel-Razzak Z, Jouan E, Stieger B, Denizot C, Parmentier Y, and Fardel O (2016) Alteration of human hepatic drug transporter activity and expression by cigarette smoke condensate. Toxicology 363-364:58-71.

Schneider CA, Rasband WS, and Eliceiri KW (2012) NIH Image to ImageJ: 25 years of image analysis. Nat Methods 9:671-675.

Sharanek A, Burban A, Humbert L, Bachour-El Azzi P, Felix-Gomes N, Rainteau D, and Guillouzo A (2015) Cellular accumulation and toxic effects of bile acids in cyclosporine A-treated HepaRG hepatocytes. Toxicol Sci 147:573-587.

Song CS, Echchgadda I, Baek BS, Ahn SC, Oh T, Roy AK, and Chatterjee B (2001) Dehydroepiandrosterone sulfotransferase gene induction by bile acid activated farnesoid $\mathrm{X}$ receptor. $J$ Biol Chem 276:42549-42556.
Stanley EL, Hume R, and Coughtrie MW (2005) Expression profiling of human fetal cytosolic sulfotransferases involved in steroid and thyroid hormone metabolism and in detoxification. $\mathrm{Mol}$ Cell Endocrinol 240:32-42.

Sueyoshi T, Green WD, Vinal K, Woodrum TS, Moore R, and Negishi M (2011) Garlic extract diallyl sulfide (DAS) activates nuclear receptor CAR to induce the Sult le1 gene in mouse liver. PLoS One 6:e21229.

Tsuji S, Kawamura F, Kubiura M, Hayashi A, Ohbayashi T, Kazuki Y, Chesné C, Oshimura M, and Tada M (2014) Dual-color fluorescence imaging to monitor CYP3A4 and CYP3A7 expression in human hepatic carcinoma HepG2 and HepaRG cells. PLoS One 9: e104123.

Uppal H, Saini SP, Moschetta A, Mu Y, Zhou J, Gong H, Zhai Y, Ren S, Michalopoulos GK, Mangelsdorf DJ, et al. (2007) Activation of LXRs prevents bile acid toxicity and cholestasis in female mice. Hepatology 45:422-432.

Vyhlidal CA, Gaedigk R, and Leeder JS (2006) Nuclear receptor expression in fetal and pediatric liver: correlation with CYP3A expression. Drug Metab Dispos 34:131-137.

Wang S, Yuan X, Lu D, Guo L, and Wu B (2017) Farnesoid X receptor regulates SULT1E1 expression through inhibition of PGC1 $\alpha$ binding to HNF $4 \alpha$. Biochem Pharmacol 145: 202-209

Xia Y, Stadler D, Lucifora J, Reisinger F, Webb D, Hösel M, Michler T, Wisskirchen K, Cheng X, Zhang K, et al. (2016) Interferon- $\gamma$ and tumor necrosis factor- $\alpha$ produced by $T$ cells reduce the HBV persistence form, cccDNA, without cytolysis. Gastroenterology 150:194-205.

Address correspondence to: Dr. Melissa Runge-Morris, Institute of Environmental Health Sciences, 6135 Woodward Ave, Room 2116, Wayne State University, Detroit, Ml 48202. E-mail: m.runge-morris@wayne.edu 